\title{
A heuristic approach to cultivate symbiosis in industrial clusters led by process industry
}

\author{
Amtul Samie Maqbool*, Giustino Emilio Piccolo, Brecht Zwaenepoel and Greet \\ Van Eetvelde
Ghent University, Energy \& Cluster Management, Faculty of Engineering and Architecture, Gent, Belgium
*corresponding author: ecm@ugent.be

\begin{abstract}
This paper introduces a heuristic approach for industrial symbiosis (IS) facilitators to investigate and instigate better energy and resource management via synergies across process industries. The proposed method studies the industrial system at three levels; regional, cluster and company. At the company level, in-depth information is collected using a pentagonal LESTS (Legal, Economic, Spatial, Technical, Social) survey, which is formulated after weighing the regional effects on the whole system. At the cluster level, an inventory of technological and organisational opportunities is produced, offering leverage for IS activities. A gap analysis between the IS potential of the cluster and the IS appreciation on the industrial sites is visualised via LESTS pentagons. The coupled investigation at company and cluster level results in a list of realisable IS activities, which is then translated into business strategies for each participating company using a SWOT analysis.
\end{abstract}

\section{Introduction}

Process industry transforms material resources into intermediate or end-products and holds an important place at the core of every value-chain [1]. In Europe alone, the process industry represents about $20 \%$ of the manufacturing industry (employment and turnover) [1]. This provides the opportunity to significantly improve resource and energy efficiency and the global environmental footprint of industrial activities. Current systems of resource efficiency and recycling, however, are not enough to replace extraction of virgin materials to keep at par with the increasing needs of the present society. Such improvement can only result in 50\% to $75 \%$ improvement in environmental performance [2], but in order to bring a substantial reduction in environmental burdens radical innovations are needed.

Global material consumption has doubled between 1950 and 2010 and has even accelerated during the last decade [3]. According to an estimate in 2005, globally recycled material only contributed to $6 \%$ of the total processed material, with $13 \%$ in Europe [4]. Owing to the rate at which human society is pushing the planetary boundaries [5], businesses require improved management and utilisation of energy and resources, reduction of waste and finally a circular economy. Especially in Europe, current business structures, cultures and practices are evolving, opening windows for new ideas and innovations [6] within and across process sectors. 
In the past, collaborations between companies of a sector have grown organically, starting from a wish, a need or a duty to collaborate $[7,8]$. Industrial Symbiosis (IS) examines cooperative management of resource flows [9] between businesses. IS engages traditionally separate entities in a collective approach to competitive advantage [10] involving, on one hand, physical exchange of materials, energy, water, and by-products, and on the other hand social tactics at the firm and multiorganisational level [11]. Based on the principle that businesses working together can strive for a collective economic and ecological benefit that is greater than the sum of individual benefits each company can achieve [10, 4], the European Commission adopted an ambitious package on circular economy in mid-2016. The circular economy package includes roadmaps and action plans towards sustainable economic development including concrete measures to promote reuse of materials and to stimulate IS [14], hence also introducing legislative changes related to waste registration and handling of resources.

Despite the incentives, practical implications to achieve symbiosis activities are complex due to the intra-cooperative level at which the resources are treated and the way regulations are built around this process [15]. Legal inconveniences, economic barriers such as the lack of financial profit, as well as spatial, technological and social boundaries, can all lead to failing cooperation [7] . Hence, there is a need to bridge the gap between bottom-up appreciation of IS by businesses and the topdown policies at national or international level.

In support of tackling these challenges, this paper presents a heuristic approach to cultivate cross-sectorial industrial symbiosis. Building on consolidated studies in the field of business park management [7], a systemic methodology to identify IS opportunities across process industries is developed. The proposed methodology is applied to a selection of three self-organising cross-sectorial industrial clusters in Europe, under the H2020 project 'EPOS' [16]. These clusters involve two or more process industries from five different sectors: steel, chemicals, minerals, cement and engineering. Taking into account the characteristics of the process industries analysed, the industrial clusters are placed in a system's perspective with the aim to investigate, instigate and initiate IS collaborations, and to turn the industrial clusters into eco-clusters.

The paper first introduces the methodology and then defines three systemic levels, each with a unique set of impacts and precursors for IS. An exemplary result is discussed for one EPOS cluster, followed by a conclusion with recommendations for applying the methodology.

\section{LESTS methodology}

In order to propose an approach based on existing industrial clusters and to deal with the complexity of the industrial clusters, the frame is set in systems perspective and LESTS (Legal, Economic, Spatial, Technical and Social) approach is applied to capture the multidisciplinary aspects that influence industrial symbiosis. 


\subsection{LESTS approach}

The pentagonal approach of LESTS was developed to assess the appreciation of existing resources at a business park and provide a set of guidelines for better park management. The LESTS book series [7] has served as a practical basis for building the LESTS methodology for IS facilitators in industry clusters.

\begin{tabular}{|c|c|c|c|c|c|c|}
\hline & Legal & Economic & Spatial & Technical & Social & \\
\hline 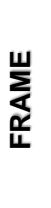 & $\begin{array}{c}\text { policy } \\
\text { context } \\
\text { framing cluster } \\
\text { agreements }\end{array}$ & $\begin{array}{l}\text { economic } \\
\text { instruments } \\
\text { sponsoring } \\
\text { cluster } \\
\text { management }\end{array}$ & $\begin{array}{l}\text { regional } \\
\text { planning } \\
\text { organising } \\
\text { cluster design }\end{array}$ & $\begin{array}{c}\text { equipment \& } \\
\text { infrastructure } \\
\text { supporting } \\
\text { cluster } \\
\text { activities }\end{array}$ & $\begin{array}{c}\text { societal } \\
\text { challenges } \\
\text { answering } \\
\text { cluster } \\
\text { stakeholders }\end{array}$ & \\
\hline $\begin{array}{l}z \\
z \\
0 \\
1 \\
0 \\
0\end{array}$ & $\begin{array}{l}\text { no legal ground } \\
\text { nor contracts } \\
\text { in place } \\
\text { contractual } \\
\text { multi-party } \\
\text { clustering }\end{array}$ & $\begin{array}{c}\text { no wins } \\
\text { recognised, } \\
\text { gains internalised } \\
\text { entity in } \\
\text { place driving } \\
\text { symbiosis }\end{array}$ & $\begin{array}{l}\text { no proximity } \\
\text { nor connection } \\
\text { options } \\
\text { integrated } \\
\text { in regional } \\
\text { planning }\end{array}$ & $\begin{array}{c}\text { no technical } \\
\text { feasibility } \\
\text { circular } \\
\text { economy } \\
\text { principles met }\end{array}$ & $\begin{array}{c}\text { no awareness } \\
\text { nor acceptance }\end{array}$ & 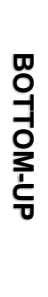 \\
\hline
\end{tabular}

Fig. 1. LESTS framework adapted from [7]

In the adapted LESTS approach, the IS facilitator assumes the role of park or site manager and follows a roadmap to identify IS opportunities for the process industries in a (cross-) sectorial cluster. The proposed methodology incorporates the LESTS considerations into IS identification and initiation process and hence brings a holistic view of the system, by adding both technological and non-technological information under one umbrella as shown in Fig. 1. Within each LESTS domain the framework for managing cluster activities is investigated and the level of collaboration is scored from a top-down as well as bottom-up perspective. When the data is collected at the company level, the bottom-up approach is used to investigate the potential to start symbiosis activities (as used in this study). When the information is collected from a park manager or a cluster manager, it follows a top-down approach of implementing symbiosis in the industrial cluster. The arrows suggest the progressive stages of an industrial network (scored 0-5) when symbiotic relationships are formed and mature over time. The intermediate stages of industrial clusters are detailed in Table 1.

Aiming for sustainability progress in industrial systems is a challenging task. Interactions across companies or process sectors make up the industrial cluster, which is embedded in a regional system, which in turn is surrounded by the global system. The IS facilitator should understand these hierarchies and envision system trends that promote a more sustainable future. 


\section{System hierarchies}

For investigating industrial clusters, a systems approach is adopted. A system is viewed as a composite of subsystems that form a unitary whole [17]. The core conceptualisation in systems thinking is that by understanding the structure of the system (elements and relations) its behaviour can be explained [18], understood and managed. An industrial cluster is a complex system. It includes a high number of companies and actors, which interact among each other in many different and unpredictable ways. In addition to being complex, an industrial cluster is also dynamic and adaptive. Being dynamic means that industrial cluster evolves through a non-linear path, highly influenced by the contextual framework (global effects) and hard to predict based only on the initial condition of the system [19].

A typical relation in an industrial cluster is not a linear cause and effect. The variables, the different system's components and the elements of each component (e.g. people, businesses, governments), are constantly interacting and changing, in response to each other and to external pressures, creating non-linear feedback loops (Sanders, 2008). This results in an emergent behaviour [13] and defines the unique properties that distinguish each cluster from the others. In this study, three different EPOS industrial production sites, operated and managed by multi-national companies are considered as the basic elements of the industrial system. These industrial sites are defined by a system boundary, across which they communicate with their environment, as shown in Fig. 2. This can be exchanging materials, energy, utilities, information, culture, people, or sharing infrastructure, services, resources with other companies, with society or with the ecosphere [20].

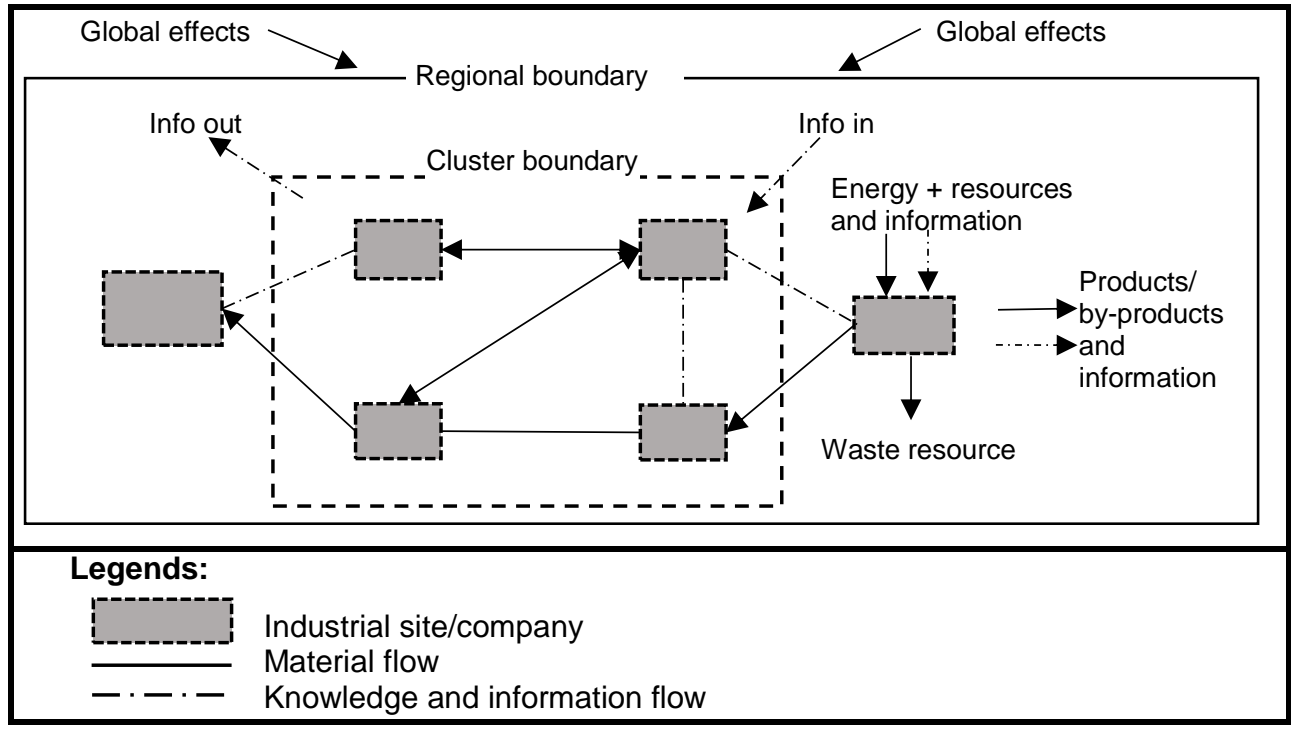

Fig. 2. System hierarchies and the interactions within 


\section{System hierarchies applied to case study}

To capture the intrinsic complexity and dynamism of each industrial cluster, the LESTS methodology is applied in the clusters to investigate IS possibilities around the selected process industries. The system effects are studied at three levels; regional, cluster and company in the following manner.

\subsection{Regional}

At the regional level, two LESTS aspects are most prominent; the policy context and regional planning rules. These two aspects define the envisioned development direction for the region and outline the system drivers or hurdles towards resource and energy efficiency. Since the industrial system exists within a global system, it is effected by contextual elements that are factored through weighing. Examples are bio-based or circular economies, pull \& push market forces, availability of utility networks, planning instruments for renewable energies, the geo-political state of affairs affecting the supply chain, etc. This helps to identify the possible constraints and drivers of IS and streamline the focus of the surveys developed for the individual site analysis.

For the EPOS clusters, the evolving European regulation defines the threshold for the impact of all proposed IS projects. The literature review of technological advancements of individual process industry established the drivers and bottlenecks for IS projects that were proposed to individual industry. Theoretically this stage of system study is followed by a cluster level analysis; in this study the company level analysis preceded the cluster level analysis. For practical reasons, the data collected at company level were also used to draw inferences for the characteristics of the clusters.

\subsection{Cluster}

At this level, the IS facilitator carries out an inventory of the cluster elements. Used and unused; material and energy resources, business and social networking platforms, IS facilitation opportunities, potential IS partners in the vicinity, trust building events between potential partners, information exchange linkages, access to local public or private (financial and non-financial) incentives, common linkages between individual companies, stakeholder knowledge, social networks, and other characteristics intrinsic to the cluster, are taken into account.

Based on this inventory and feedback from the LESTS surveys and in-depth studies at the company level, a gap analysis is carried out to exhibit the unused potential of available resources. For the EPOS industrial clusters, the surveys and interviews carried out at the company level helped to draw inference about the level of interconnectivity of businesses in each cluster. 
A holistic perspective is applied for identifying the system trends that support IS by using the LESTS framework. The ranking provided in Table 1 helps to visualise the results of the gap analysis by plotting the existing potential of IS against the realised IS activities. For each of the five aspects, a different set of leverages is presented, which could be exploited by the actors within the industrial cluster. Each aspect was translated into a survey question for the companies. The survey answers and interview responses were coupled with the literature review to infer the connectivity level of industries within their respective clusters. These inferences were plotted on a pentagon, showing the level that can be achieved by the cluster and the level that was actually in place at the time of data gathering.

Table 1. Ranking system for visualisation of LESTS pentagon

\begin{tabular}{|c|c|c|c|c|c|}
\hline & Legal & Economic & Spatial & Technical & Social \\
\hline 0 & $\begin{array}{c}\text { no legal ground } \\
\text { nor contracts in } \\
\text { place }\end{array}$ & $\begin{array}{c}\text { no wins } \\
\text { recognised, } \\
\text { gains internalised }\end{array}$ & $\begin{array}{r}\text { no proxin } \\
\text { conne } \\
\text { optic }\end{array}$ & $\begin{array}{l}\text { not technically } \\
\text { feasible }\end{array}$ & $\begin{array}{l}\text { no awareness } \\
\text { nor acceptance }\end{array}$ \\
\hline 1 & \begin{tabular}{|c|} 
unilateral \\
contracts in place \\
for diverse \\
activities
\end{tabular} & $\begin{array}{c}\text { incentives for } \\
\text { collective wins } \\
\text { but not in place }\end{array}$ & $\begin{array}{c}\text { local potential but } \\
\text { not in place }\end{array}$ & $\begin{array}{l}\text { similar } \\
\text { but or } \\
\text { sepa }\end{array}$ & $\begin{array}{r}\text { no join } \\
\text { towards } \\
\text { staker }\end{array}$ \\
\hline 2 & $\begin{array}{c}\text { unilateral } \\
\text { contracts in place } \\
\text { for similar } \\
\text { activities }\end{array}$ & $\begin{array}{c}\text { simple win-win } \\
\text { clustering in } \\
\text { place }\end{array}$ & $\begin{array}{l}\text { local/individual } \\
\text { connections* in } \\
\text { place }\end{array}$ & $\begin{array}{r}\text { local } r \\
\text { joi } \\
\text { ansv }\end{array}$ & $\begin{array}{r}\text { joint } \\
\text { focuse } \\
\text { emp }\end{array}$ \\
\hline 3 & $\begin{array}{c}\text { bilateral } \\
\text { contracts in } \\
\text { place, between } \\
\text { parties/ } \\
\text { providers }\end{array}$ & $\begin{array}{l}\text { generic win-win } \\
\text { collaborations } \\
\text { managed }\end{array}$ & $\begin{array}{l}\text { site design } \\
\text { supportive of } \\
\text { clustering* }\end{array}$ & $\begin{array}{r}\text { ba } \\
\text { opport } \\
\text { shar } \\
\text { clus }\end{array}$ & $\begin{array}{l}r- \\
\text { ted } \\
{ }^{2} \& \\
\mathrm{~ms}\end{array}$ \\
\hline 4 & $\begin{array}{l}\text { multi-lateral } \\
\text { agreements in } \\
\text { place }\end{array}$ & $\begin{array}{l}\text { entity } \\
\text { that off } \\
\text { \& optio }\end{array}$ & $\begin{array}{l}\text { district } \\
\text { approach to } \\
\text { clustering }\end{array}$ & $\begin{array}{r}\text { oppor } \\
\text { jo } \\
\text { opti }\end{array}$ & $\begin{array}{c}\text { active } \\
\text { stakeholder } \\
\text { networks } \\
\text { (cluster, district) }\end{array}$ \\
\hline 5 & $\begin{array}{l}\text { contractual multi- } \\
\text { party clustering }\end{array}$ & $\begin{array}{c}\text { entity in place } \\
\text { that drives IS ( } 3^{\text {rd }} \\
\text { party beneficiary) }\end{array}$ & $\begin{array}{l}\text { integrated in } \\
\text { regional } \\
\text { planning }\end{array}$ & $\begin{array}{l}\text { principles of } \\
\text { circular } \\
\text { economy met }\end{array}$ & $\begin{array}{l}\text { proactivity } \\
\text { towards any } \\
\text { social actor }\end{array}$ \\
\hline
\end{tabular}

${ }^{*}$ All options in the ranking assume interactions \& exchanges between parties in clusters, focused on materials, infrastructure and services. 


\subsection{Industrial site/ company}

Company or an individual industrial site, is the key level for IS activities. The actors at the company level have much more knowledge of the technological and organisational drivers and barriers of IS and hence an in-depth analysis is possible. Quantitative methods for material consumption, such as Material Flow Analysis of the industrial site, Life-cycle Analysis can be applied to gather information about the hotspots for IS. In this study, qualitative data collection via an LESTS survey and semi-structured interviews was carried out, regarding all activities on an industrial site that may support or hinder IS with other partners.

The framework of LESTS survey was built around three major activities on an industrial site, which includes; 1) production of by-products, waste and emissions; 2) utilisation of energy, water, equipment and infrastructure; and 3) requirement of packaging, logistics and storage. Related to each factor, information was collected on existing collaborations with neighbouring companies; nature and length (time) of these collaborations and finally; a possibility to extend these collaborations to other industry partners. The LESTS survey was supplemented with semi-structured interviews with key company representatives (often, site manager, energy/environmental manager) to collect information about the interaction and consultation between stakeholders at the cluster level. The interview focused on gaining insight into the decision making power of the site, stakeholder engagement at the cluster level, communication with neighbouring communities. These interviews helped to gain an overview of stakeholder perception about possibilities of IS activities.

In essence, LESTS surveys lead to a longlist of potential exchanges and interactions between the companies - and even municipal communities - in the region. Via consecutive SWOT analyses, indicating strengths and weaknesses (internal factors) that induce opportunities or point to threats (external factors) viable symbiosis opportunities are put forth, consequently, building a framework to identify and formulate business strategies. The potential IS opportunities are further developed into IS business cases and calculated for their sustainability improvements, considering the three pillars of sustainability (Van Eetvelde et al., 2005). To identify the opportunities of IS that are sustainable in nature, leverage is created when the principles of cleaner production are in place, a commitment to CSR has been incorporated into company policy, company is inclined to minimising its footprint or when good management practices are already in place.

\section{Results}

The described LESTS methodology resulted in identifying a number of IS activities within each cluster. To provide an exemplary result on the applicability of this methodology, IS opportunities from one cluster are presented in Fig. 3. The identified opportunities have been communicated to the respective industries and are currently under study for techno-economic feasibility. 


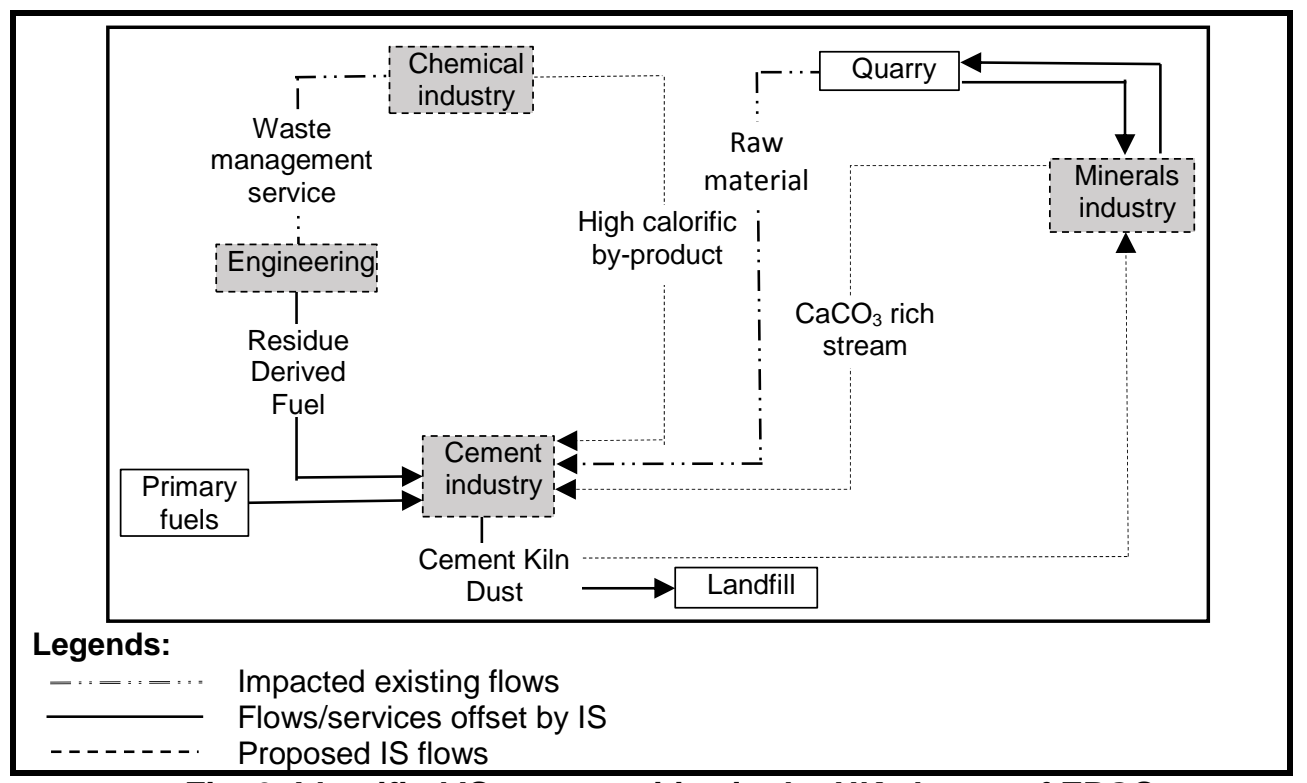

Fig. 3. Identified IS opportunities in the UK cluster of EPOS

The application of the heuristic method presented in this paper provided two sets of results. One for the cluster level and one for the companies within the cluster, willing to involve in an industrial symbiosis. The results for the cluster level visualise the gap between possibilities to engage in IS and the realisation of these possibilities by actors in the cluster as shown in Fig. 4. The outer pentagon indicates the leverage provided by the unique properties of the cluster, which arise due to the presence of diverse actors and the linkages formed between them. The inner pentagon exhibits the level to which these opportunities are availed by the actors in the cluster to form symbiosis activities.

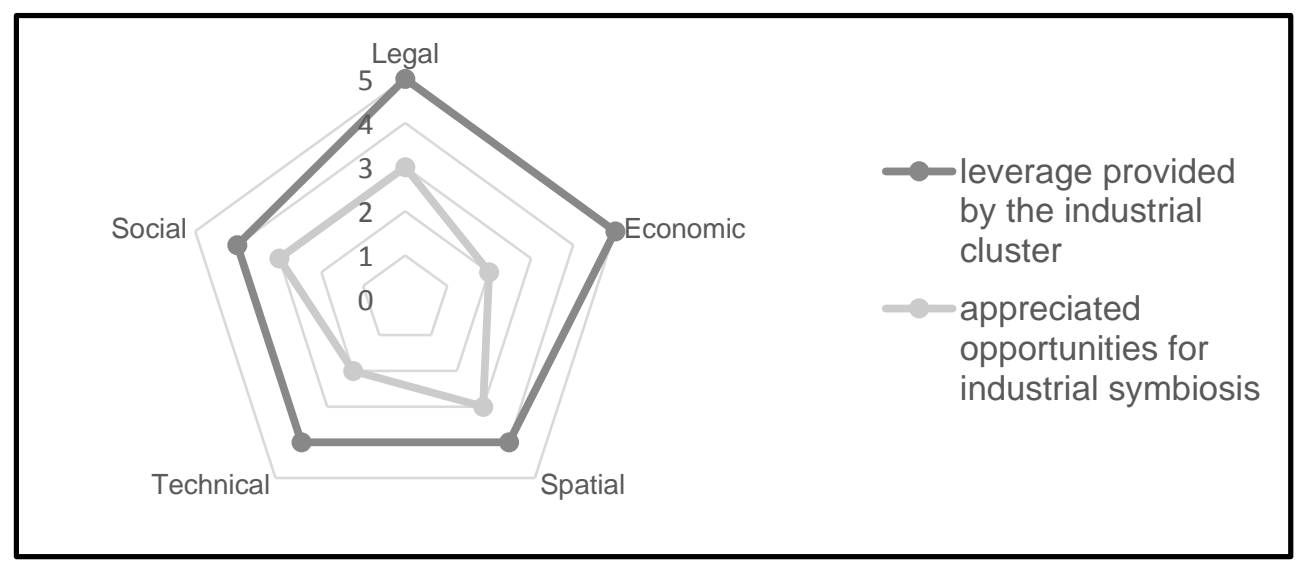

Fig. 4. The gap analysis visualised in an LESTS pentagon 
The second set of results for the individual companies is provided in a list of IS possibilities and SWOT strategies to realise the presented IS opportunities. The SWOT analysis of individual companies are communicated individually to each company and are handled under confidentiality agreement between the IS facilitator and the company.

\section{Conclusion}

The proposed methodology for facilitating industrial symbiosis answers to the needs of process industries active in (cross-)sectorial clusters and willing to improve their energy and resource profile through collaboration. The approach takes a system perspective: it provides flexibility, desired by industrial actors and leads to stability, required by the global society. The LESTS surveys, coupled with semistructured interviews, proved adequate to identify IS options in cross-sectorial clusters. Still cluster level analysis is perceived as a daunting task and requires many resources (time and costs). Likewise, the identification of key site actors for interviews is a crucial element for the success of the survey and the consecutive implementation of symbiosis activities. With an IS facilitator appointed and key contacts per industrial site identified, a good understanding of the industrial cluster, its actors and potential can be reached through regular exchange of information. Even so, socio-economic benefits are essential to attract and hold a company's interest in symbiosis activities.

Due to the EPOS project boundaries and consortium agreements, only the project partners in each industrial cluster were approached for interviews and surveys. To fully assess an industrial cluster however, it is recommended to include a maximum number of cluster actors in the analysis. The methodology provides enough flexibility to be coupled with different analyses at the company level (product life cycle), as well as, at the cluster level (material flow, environmentally extended Input Output, Social Network).

By applying the methodology at each industrial site in the EPOS project, a longlist of IS activities was identified. In a next step, techno-economic feasibility studies will be performed and the expected environmental improvement will be calculated per industrial site as well as for each cluster as a whole. Current research explores the possibility to model the complex adaptive systems of industrial clusters and predict/ascertain the behaviour of the individual actors with agent based modelling.

\section{Acknowledgment}

The research leading to these results has received funding from the European Union's Horizon 2020 research and innovation programme under grant agreement no. 679386, EPOS project (Enhanced energy and resource Efficiency and Performance in process industry Operations via onsite and cross-sectorial Symbiosis). The sole responsibility of this publication lies with the authors. The European Union is not responsible for any use that may be made of the information contained therein. 


\section{References}

[1] P. Tello and R. Weerdmeester, "SPIRE Roadmap," SPIRE (2013)

[2] A. Tukker, "Leapfrogging into the future: developing for sustainability," Int. J. Innov. Sustain. Dev., vol. 1, no. 1, pp. 65-84, (2005)

[3] A. Schaffartzik, A. Mayer, S. Gingrich, N. Eisenmenger, C. Loy, and F. Krausmann, "The global metabolic transition: Regional patterns and trends of global material flows, 1950-2010," Glob. Environ. Change, vol. 26, pp. 87-97 (2014)

[4] W. Haas, F. Krausmann, D. Wiedenhofer, and M. Heinz, "How Circular is the Global Economy?: An Assessment of Material Flows, Waste Production, and Recycling in the European Union and the World in 2005," J. Ind. Ecol., vol. 19, no. 5, pp. 765-777 (2015)

[5] J. Rockström et al., "Planetary Boundaries: Exploring the Safe Operating Space for Humanity," Ecol. Soc. (2009)

[6] J. Grin, J. Rotmans, and J. Schot, Transitions to Sustainable Development: New Directions in the Study of Long Term Transformative Change. Routledge (2010)

[7] G. Van Eetvelde et al., Groeiboeken Duurzame BedrijvenTerreinen juridisch, economisch, ruimtelijk, tech-nisch bekeken. Vanden Broele Grafische Groep, (2005)

[8] G. Van Eetvelde, K. Deridder, S. Segers, T. Maes, and M. Crivits, "Sustainability scanning of eco-industrial parks.," presented at the In 11th European Roundtable on Sustainable consumption and Production (ERSCP). (2007)

[9] E. A. Lowe and L. K. Evans, "Industrial ecology and industrial ecosystems," J. Clean. Prod., vol. 3, no. 1, pp. 47-53, Jan (1995)

[10] M. R. Chertow, "Industrial Symbiosis: Literature and Taxonomy," Annu. Rev. Energy Environ., vol. 25, no. 1, pp. 313-337 (2000)

[11] M. C. Ruiz Puente, E. R. Arozamena, and S. Evans, "Industrial symbiosis opportunities for small and medium sized enterprises: preliminary study in the Besaya region (Cantabria, Northern Spain)," J. Clean. Prod., vol. 87, pp. 357-374 (2015)

[12] N. B. Jacobsen, "Industrial Symbiosis in Kalundborg, Denmark: A Quantitative Assessment of Economic and Environmental Aspects," J. Ind. Ecol., vol. 10, no. 1-2, pp. 239-255 (2006)

[13] M. Chertow and J. Ehrenfeld, "Organizing Self-Organizing Systems," J. Ind. Ecol., vol. 16, no. 1, pp. 13-27 (2012)

[14] European Commission, "Circular Economy Strategy," European Commission Environment, Brussels, Belgium, EU Action plan COM/2015/0614 final (2016)

[15] A. Golev, G. D. Corder, and D. P. Giurco, "Barriers to Industrial Symbiosis: Insights from the Use of a Maturity Grid," J. Ind. Ecol., vol. 19, no. 1, pp. 141-153 (2015)

[16] "EPOS," Enhanced energy and resource Efficiency and Performance in process industry Operations via onsite and cross-sectorial Symbiosis / SPIRE. [Online]. Available: https://www.spire2030.eu/EPOS. [Accessed: 26-Jan-2017].

[17] L. Von Bertalanffy, General System theory: Foundations, Development, Applications. New York, (1968).

[18] N. Frantzeskaki, "Dynamics of societal transitions; driving forces and feedback loops," TU Delft, Delft University of Technology, (2011)

[19] V. Albino, L. Fraccascia, and I. Giannoccaro, "Exploring the role of contracts to support the emergence of self-organized industrial symbiosis networks: an agent-based simulation study," J. Clean. Prod., vol. 112, Part 5, pp. 4353-4366, (2016)

[20] H. P. Wallner, "Towards sustainable development of industry: networking, complexity and eco-clusters," J. Clean. Prod., vol. 7, no. 1, pp. 49-58 (1999) 